\title{
Retraction
}

\section{Retraction: Inhibition of RelA phosphorylation sensitizes chemotherapeutic agents-mediated apoptosis in constitutive NF-kappaB-expressing and chemoresistant cells}

\author{
SK Manna, P Manna and A Sarkar
}

Cell Death and Differentiation (2013) 20, 784; doi:10.1038/cdd.2013.18; published online 1 March 2013

Retraction to: Cell Death and Differentiation (2007) 14: 158-170, Subsequent 'Corrigendum' in Cell Death and Differentiation (2012) 19: 1572

The corresponding author wishes to retract the above paper for the reason that the images in some of the Figure panels in the paper could not unambiguously be attributed in the laboratory notebooks. Thus, the results presented in this paper are not fully supported by the available laboratory records. All the authors have agreed to sign this retraction notice. We deeply regret this circumstance and apologize for any adverse consequences that this retraction might cause to the scientific community. 